\title{
BMJ Open Mini-sternotomy versus conventional sternotomy for aortic valve replacement: a randomised controlled trial
}

\author{
Helen C Hancock (D) , ${ }^{1}$ Rebecca H Maier (D) , ${ }^{1}$ Adetayo Kasim, ${ }^{2}$ James Mason, ${ }^{3}$ \\ Gavin Murphy, ${ }_{4}^{4}$ Andrew Goodwin, ${ }^{5}$ W Andrew Owens (i) , ${ }^{5}$ Enoch Akowuah (D) ${ }^{5}$
}

To cite: Hancock HC, Maier RH, Kasim A, et al. Ministernotomy versus conventional sternotomy for aortic valve replacement: a randomised controlled trial. BMJ Open 2021;11:e041398. doi:10.1136/ bmjopen-2020-041398

- Prepublication history and additional material for this paper are available online. To view these files, please visit the journal online (http://dx.doi. org/10.1136/bmjopen-2020041398).

Received 08 June 2020

Revised 04 December 2020

Accepted 07 December 2020

Check for updates

(c) Author(s) (or their employer(s)) 2021. Re-use permitted under CC BY-NC. No commercial re-use. See rights and permissions. Published by BMJ.

For numbered affiliations see end of article.

Correspondence to

Enoch Akowuah;

enoch.akowuah@nhs.net

\section{ABSTRACT}

Objective To compare clinical and health economic outcomes after manubrium-limited mini-sternotomy (intervention) and conventional median sternotomy (usual care).

Design A single-blind, randomised controlled trial. Setting Single centre UK National Health Service tertiary hospital.

Participants Adult patients undergoing aortic valve replacement (AVR) surgery.

Interventions Intervention was manubrium-limited mini-sternotomy performed using a 5-7 cm midline incision. Usual care was median sternotomy performed using a midline incision from the sternal notch to the xiphisternum.

Primary and secondary outcome measures The primary outcome was the proportion of patients who received a red cell transfusion postoperatively and within 7 days of index surgery. Secondary outcomes included proportion of patients receiving a non-red cell blood component transfusion and number of units transfused within 7 days and during index hospital stay, quality of life and cost-effectiveness analyses.

Results 270 patients were randomised, received surgery and contributed to the intention to treat analysis. No difference between mini and conventional sternotomy in red-cell transfusion within 7 days was found; 23/135 patients in each arm received a transfusion, OR 1.0 (95\% $\mathrm{Cl} 0.5$ to 2.0$)$ and risk difference $0.0(95 \% \mathrm{Cl}-0.1$ to 0.1 ). Mini-sternotomy reduced chest drain losses (mean $181.6 \mathrm{~mL}$ (SD 138.7) vs conventional, mean $306.9 \mathrm{~mL}$ (SD 348.6)); this did not reduce red-cell transfusions. Mean valve size and postoperative valve function were comparable between mini-sternotomy and conventional groups; $23 \mathrm{~mm}$ vs $24 \mathrm{~mm}$ and 6/134 moderate or severe aortic regurgitation vs $3 / 130$, respectively. Mini-sternotomy resulted in longer bypass (82.7 $\mathrm{min}$ (SD 23.5) vs $59.6 \mathrm{~min}$ (SD 15.1)) and cross-clamp times (64.1 min (SD 17.1) vs 46.3 min (SD 10.7)). Conventional sternotomy was more cost-effective with only a $5.8 \%$ probability of ministernotomy being cost-effective at a willingness to pay of $£ 20$ 000/QALY (Quality Adjusted Life Years).

Conclusions AVR via mini-sternotomy did not reduce red blood cell transfusion within 7 days following surgery when compared with conventional sternotomy.

Trial registration number ISRCTN29567910; Results.

\section{Strengths and limitations of this study}

- Large proportion of eligible patients recruited, and all patient randomised contributed to the primary outcome.

- Clear protocols for transfusion of blood and blood products with high adherence throughout the trial.

- Patients were blinded to group allocation until 2 days following index surgery, reducing the likelihood of bias.

- First randomised trial to perform detailed health economic evaluation of minimally invasive versus conventional sternotomy.

- The trial was undertaken by three experienced minimally invasive surgeons who were expert at both techniques.

\section{OBJECTIVES}

Aortic valve replacement (AVR) for severe symptomatic valvular disease is one of the most common cardiac surgical procedures performed worldwide. The current joint guidelines of the American College of Cardiology and American Heart Association and the current European Society of Cardiology guidelines for the management of aortic valve disease state that surgical AVR is recommended for symptomatic patients with severe aortic stenosis and asymptomatic patients with severe aortic stenosis who meet an indication for AVR when surgical risk is low or intermediate. ${ }^{1}$

In the UK, the National Adult Cardiac Surgery Audit published by National Institute for Cardiac Outcome Reporting reported 13027 procedures for aortic valve disease in the UK from April 2018 to March 2019. ${ }^{2}$ Outcomes are generally excellent with in-hospital observed mortality in the UK of $1.5 \%$ for first-time elective procedures. ${ }^{3}$ In low-risk patients with a EuroSCORE 2 of less than 4, a mortality of less than $0.7 \%$ was observed in over 15000 patients undergoing AVR surgery in the UK between 2016 and 2019. ${ }^{2}$ 
These results are not observed in all patients; in highrisk groups, conventional surgery risks perioperative organ injury and prolonged recovery, with death in up to $31 \%$ of patients within 1 year. ${ }^{4}$ Minimally invasive surgery combines the durability of surgical repair with reductions in surgical trauma that should reduce perioperative morbidity. Observational analyses demonstrating reductions in morbidity and resource use ${ }^{56}$ may be confounded by multiple sources of bias and are at odds with limited evidence from randomised controlled trials (RCTs) that have not shown improved outcomes. ${ }^{7}$ This uncertainty is reflected by variations in uptake internationally. ${ }^{8-10}$

The move towards minimally invasive surgery is also driven by patient perceptions of pain reduction and rapid recovery. However, minimally invasive cardiac surgery is not without risks; limiting access to the heart can result in technically suboptimal surgery, including concern about the size of the prosthesis that can be inserted and paravalvular leak rates.

This trial evaluated manubrium-limited ministernotomy versus conventional sternotomy for aortic valve replacement (MAVRIC). We hypothesised that mini-sternotomy would reduce red cell transfusion rates, a contemporary marker of surgical trauma and indicator of adverse outcomes ${ }^{11}$; this has been contested, ${ }^{12}$ though the evidence is not conclusive. ${ }^{13}$ An embedded costeffectiveness analysis evaluated whether the intervention was cost effective in a UK National Health Service (NHS) setting.

\section{PATIENTS AND METHODS}

\section{Trial design}

MAVRIC was a single-centre, single-blind, RCT comparing AVR via manubrium-limited mini-sternotomy group (intervention) and AVR via conventional sternotomy group (usual care). An NHS Research Ethics Committee approved the trial, which was conducted in accordance with the principles of the International Conference on Harmonisation of Good Clinical Practice. ${ }^{14}$ South Tees Hospitals NHS Foundation Trust was the sponsor and recruiting centre.

\section{Patient and public involvement}

In designing the study, we asked patients their view on what factors may affect whether they took part in the study. This was done in an outpatient setting and via a postal questionnaire. They felt expertise was important. Most patients felt that although the cosmetic benefit of the minimally invasive approach was appealing, they expected some clinical benefit from minimally invasive surgery as well. Importantly, most patients said they would accept being blind to the type of surgery they had received for 48 hours after the procedure.

\section{Participants}

Patients were eligible if they were aged 18 years or over; required first-time, non-emergency, isolated AVR surgery and were willing to provide written informed consent. Full details of the eligibility criteria are in the online supplemental material.

\section{Randomisation}

Eligible patients were randomised by members of the research team using a 24-hour, central, secure, webbased randomisation system with concealed allocation, managed by the Clinical Trials Unit; randomisation was in a 1:1 ratio between mini and conventional sternotomy and stratified by baseline logistic EuroSCORE and preoperative haemoglobin $(\mathrm{Hb})$.

\section{Interventions}

Manubrium-limited mini-sternotomy was performed using a 5-7 cm midline skin incision dividing the manubrium from the sternal notch to $1 \mathrm{~cm}$ below the manubrium-sternal junction. Cardiopulmonary bypass was established with an ascending aortic cannula and percutaneous femoral venous cannulation. Conventional median sternotomy was performed using a midline incision from the sternal notch to the xiphisternum. Key aspects of anaesthesia were standardised and are detailed in the protocol. ${ }^{15}$

\section{Blinding}

All patients were blinded to the type of sternotomy received until after their day 2 quality of life and pain assessments. All patients had trial-specific opaque dressings applied to their sternal wound and groin before leaving theatre.

\section{Transfusion protocol}

The postoperative period, and trial protocol in relation to red cell and non-red cell transfusion, began on admission to the cardiothoracic intensive care unit; it specified that patients should receive a red cell transfusion if their $\mathrm{Hb}$ dropped below $80 \mathrm{~g} / \mathrm{L}$ or were bleeding by $400 \mathrm{~mL} /$ hour or more, or were bleeding $100 \mathrm{~mL} /$ hour or more for 4 or more hours with an $\mathrm{Hb}$ equal to or greater than $80 \mathrm{~g} / \mathrm{L}$ or had blood loss with haemodynamic instability irrespective of thromboelastography (TEG) and/or clotting profile results. One unit of red cells was transfused and $\mathrm{Hb}$ level checked before transfusing another unit.

Participants received a non-red cell transfusion if both of the following criteria were met: bleeding defined by $400 \mathrm{~mL} /$ hour or more or blood loss of $100 \mathrm{~mL} /$ hour or more for 4 hours or more; TEG or coagulation-guided transfusion indicated.

\section{Outcomes}

All outcomes were measured from index surgery.

\section{Primary outcome}

The primary outcome was the proportion of patients who received a red cell transfusion postoperatively and within 7 days of index surgery. 


\section{Secondary outcomes}

- Proportion of patients receiving a red cell transfusion and number of units transfused within 7 days and during index hospital stay.

- Proportion of patients receiving a non-red cell blood component transfusion and number of units transfused within 7 days and during index hospital stay.

- Volume in chest drains at 6 and 12 hours and drain removal.

- Degree of aortic regurgitation using echocardiogram within 6 weeks.

- Re-operation rates.

- Conversion to conventional AVR during surgery.

- Changes in lung function at 4 days and 6 weeks.

- Quality of life EuroQol (EQ-5D-3L, EQ-VAS) at 2 days, 6 and 12 weeks.

- Time patients are deemed 'fit for discharge'.

- Healthcare utilisation to 12 weeks.

- Cost and cost-effectiveness analyses.

- Adverse events to 12 weeks.

\section{Statistical analysis}

Audit data had indicated $30 \%$ of patients undergoing AVR via conventional sternotomy (15 of 50 patients) received a red cell transfusion compared with $13 \%$ of patients ( 8 of 60 patients) undergoing AVR via mini-sternotomy. Using Fisher's exact test, 90\% power, 5\% alpha, we estimated that 260 patients would be required to detect a $17 \%$ reduction in the proportion of patients requiring a red cell transfusion (13\% compared with $30 \%)$, using a two-sided test. Allowing for loss to follow-up, the sample size was increased to 270 .

The primary analysis was based on intention-to-treat principles, in accordance with a pre-specified statistical analysis plan.

The primary efficacy analysis was based on a logistic regression model with only group (minimally invasive and conventional) and stratifying factors (baseline logistic EuroSCORE and $\mathrm{Hb}$ ) as the predictors. ORs and their associated $95 \%$ CIs are reported in the primary analysis. Sensitivity analysis using alternating logistic regression was performed for the primary endpoint to sensitise for surgeon effects; the odds of receiving a red cell transfusion for two patients treated by the same surgeon was compared with two patients treated by different surgeons.

All analyses of secondary continuous efficacy endpoints at single time points were based on linear models where, if appropriate, a log normal model was fitted to sensitise the linearity assumption. Longitudinal analysis was performed for all endpoints with repeated data over time to investigate changes in trends over the trial period. The trial period was defined as baseline, up to 7 days (postoperative period), 6-week follow-up and 12-week follow-up. All analyses of binary endpoints at a single time point were based on logistic regression. Generalised estimating equation was used to analyse repeated binary data per patient to account for intrapatient correlation.

Further exploratory analysis was conducted to investigate the association between the treatment group and other

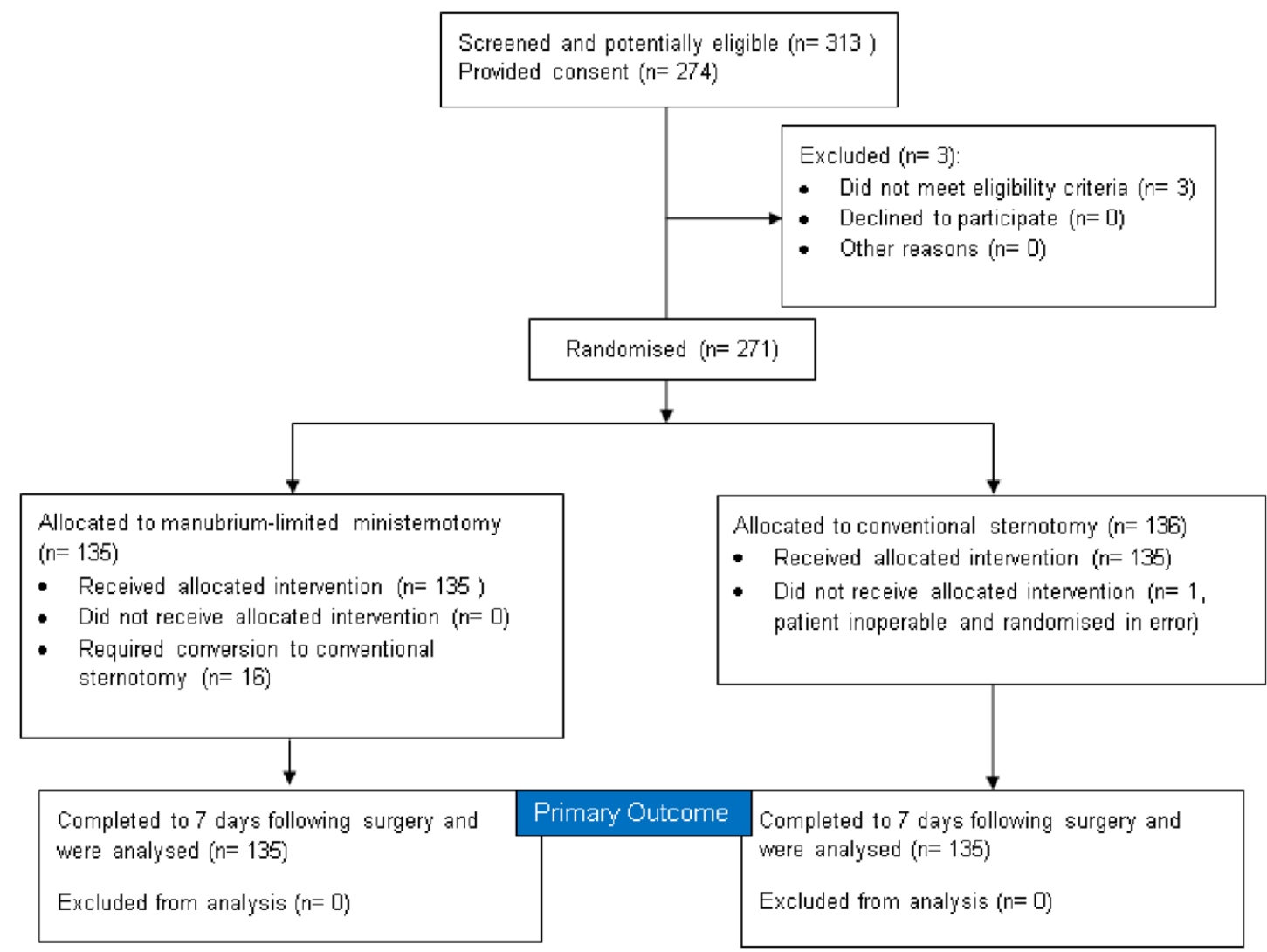

Figure 1 Consolidated Standards of Reporting Trials diagram. Flow of participants through trial. 
clinical factors. All analyses were performed using R V.3.3.3 (The R Foundation) and SAS V.9.4 (SAS Institute).

\section{Economic evaluation}

A prospective economic evaluation applying an NHS perspective, following National Institute for Health and Care Excellence reference case guidance, ${ }^{16}$ was employed. Healthcare utilisation was captured up to 3 months following discharge from index surgery. Resource use was valued in 2016 pounds sterling using national sources, ${ }^{17} 18$ and where necessary, local microcosting ( $£ 1=\mathrm{US} \$ 1.50$ ). Resources included surgery, transfusions, length of hospital stay (by level of care), complications and further surgery and community care following discharge.

Mechanisms of missingness within the data were explored and multiple imputation methods were applied to impute missing data and minimise bias, using chained equations and predictive mean matching. Imputation sets were analysed within a bivariate analysis of costs and QALYs to generate incremental within-trial cost per QALY estimates and credible intervals. Findings were presented on the incremental cost-effectiveness ratio (ICER) plane and with cost-effectiveness acceptability curves, using the net monetary benefit approach.

Imputation was conducted according to good practice guidance. ${ }^{19} 20$ Multiple imputation provides unbiased estimates of treatment effect if data are missing at random and the missingness process is adequately characterised: this assumption was explored in the data, for example, by using logistic regression for missingness of costs and QALYs against baseline variables. ${ }^{21} \mathrm{~A}$ regression model was used to generate multiple imputed datasets (or 'draws') for individual treatment groups, where missing values were predicted drawing on predictive covariates. Outcome measures and costs (at each time point) contributed as predictors and imputed variables. Each draw provided a complete dataset, reflecting the distributions and correlations between variables. Predictive mean matching drawn from the five nearest neighbours $(\mathrm{knn}=5)$ was used to enhance the plausibility and robustness of imputed values; normality was not assumed. The imputation model used fully conditional (MCMC) methods. Draws were analysed using bivariate regression (see below) within the Stata MI framework, capturing within and between variances for imputed samples. ${ }^{22}$ After examining the fraction of missing information from finite imputation sampling, 20 draws were taken in the final imputation model.

\section{RESULTS}

\section{Trial population}

MAVRIC recruited to time and target; 313 patients were considered for the trial; 274 patients consented between 20 March 2014 and 25 July 2016. The analysis population was 270 eligible patients; 135 allocated to the AVR via mini-sternotomy group and 135 allocated to the AVR via conventional sternotomy group (figure 1).
All 270 patients underwent surgery. Sixteen patients required cross-over from minimally invasive to a conventional sternotomy due to anaesthetic emergency $(n=2)$, difficulties due to vascular access $(n=9)$ and intraoperative complications $(n=5)$; further details and the number of operations performed by surgeon are in the online supplemental material.

Baseline characteristics were similar between groups (table 1).

\section{Primary outcome}

There was no difference between groups in relation to the primary outcome (table 2). The proportion of patients receiving a red cell transfusion was 23 of 135 in both groups, OR 1.0 (95\% CI 0.5 to $2.0 ; \mathrm{p}=0.9052)$ and risk difference of 0.0 ( $95 \% \mathrm{CI}-0.1$ to $0.1 ; \mathrm{p}=0.9999)$.

\section{Secondary outcomes}

Red cell and non-red cell transfusion

There was no significant difference between groups with respect to any red cell transfusion at discharge (table 2). There was no difference between groups in $\mathrm{Hb}$ from baseline to 4 days following index surgery (online supplemental material). There was a statistically significant difference in the proportion of patients receiving any non-red cell transfusion within 7 days of surgery; mini 6/135 vs conventional $18 / 135$, OR 0.3 (95\% CI 0.1 to 0.8 ; $\mathrm{p}=00137$ ) (table 3).

\section{Cross-clamp time and cardiopulmonary bypass time}

Mini-sternotomy resulted in longer cardio pulmonary bypass times; mini group $82.7 \mathrm{~min}$ ( $\mathrm{SD} 23.5$ ), conventional $59.6 \mathrm{~min}$ (SD 15.1). Aortic cross-clamp times were also longer; mini group $64.1 \mathrm{~min}$ (SD 17.1), conventional 46.3 min (SD 10.7) (table 4).

\section{Chest drain losses}

Mini-sternotomy resulted in a $40.8 \%$ reduction in chest drain losses at 12 hours, the mini group mean was 181.6 $\mathrm{mL}$ (SD 138.7), conventional group mean was $306.9 \mathrm{~mL}$ (SD 348.6); the mean difference was $-127.7 \mathrm{~mL}$ (95\% CI -191.7 to $-63.8, \mathrm{p}=0.0001$ ). At drain removal, mean difference was $-145.3 \mathrm{~mL}(95 \% \mathrm{CI}-218.1$ to-72.3; $\mathrm{p}=0.0001)$ (table 4).

\section{Ventilation time}

Ventilation time between the groups was similar; 9.6 hours (SD 5.6) in the mini group and 9.8 hours (SD 6.9) in the conventional (table 4).

\section{Intensive care unit length of stay}

There was no difference in intensive care unit length of stay between groups (online supplemental material).

\section{Postoperative pain}

There was no difference in pain scores between groups; analgesic use is also included to assist interpretation (online supplemental material). 


\section{Lung function}

There was no difference between groups in lung function at baseline. At 4 days post surgery, mean forced expiratory volume in $1 \mathrm{~s}\left(\mathrm{FEV}_{1}\right) 1123 \mathrm{~mL}(\mathrm{SD} 433)$ and forced vital capacity (FVC) $1479 \mathrm{~mL}$ (SD 583) were significantly reduced in the mini group, compared with the conventional; FEV 1321 (SD 524), FVC 1698 (SD 707). Mean

Table 1 Baseline characteristics of participants by group

Mini-

sternotomy Conventional

group sternotomy

$(n=135) \quad$ group $(n=135)$

\begin{tabular}{|c|c|c|}
\hline \multicolumn{3}{|c|}{ Baseline characteristics } \\
\hline \multicolumn{3}{|c|}{ Age (years) } \\
\hline Mean \pm SD & $69.3 \pm 9.3$ & $68.7 \pm 8.4$ \\
\hline Range & $43-85$ & $39-88$ \\
\hline \multicolumn{3}{|l|}{ Gender n (\%) } \\
\hline Male & $78(57.8)$ & $87(64.4)$ \\
\hline Female & $57(42.2)$ & $48(35.6)$ \\
\hline \multicolumn{3}{|l|}{ Ethnicity n (\%) } \\
\hline White British & $135(100)$ & $135(100)$ \\
\hline \multicolumn{3}{|c|}{ Body mass index $\left(\mathrm{kg} / \mathrm{m}^{2}\right)$} \\
\hline Mean \pm SD & $30.5 \pm 5.6$ & $30.4 \pm 6.1$ \\
\hline Range (min-max) & $19.0-45.4$ & $19.3-52.0$ \\
\hline \multicolumn{3}{|c|}{$\begin{array}{l}\text { EuroSCORE: Mean } \pm \text { SD } \\
\text { (min-max) }\end{array}$} \\
\hline Logistic & $\begin{array}{l}5.2 \pm 3.5(1.5- \\
29.5)\end{array}$ & $\begin{array}{l}5.1 \pm 3.5(1.5- \\
21.0)\end{array}$ \\
\hline II-mean & $\begin{array}{l}1.5 \pm 1.1(0.5- \\
10.2)\end{array}$ & $\begin{array}{l}1.5 \pm 1.2(0.5- \\
10.0)\end{array}$ \\
\hline
\end{tabular}

Diagnosis echocardiogram:

n (\%)

\begin{tabular}{|c|c|c|}
\hline Regurgitation & $3(2.2)$ & $8(5.9)$ \\
\hline Stenosis & $132(97.8)$ & $127(94.1)$ \\
\hline \multicolumn{3}{|c|}{ NYHA class: n (\%) } \\
\hline I & $24(17.8)$ & $18(13.3)$ \\
\hline II & $68(50.4)$ & $66(48.9)$ \\
\hline III & $40(29.6)$ & $46(34.1)$ \\
\hline IV & $3(2.2)$ & $5(3.7)$ \\
\hline
\end{tabular}

${ }^{*}$ Haemoglobin prior to

randomisation: $\mathrm{g} / \mathrm{dL}$

\begin{tabular}{lll}
\hline Mean \pm SD & $137.9 \pm 14.3$ & $137.1 \pm 16.1$ \\
\hline Range (min-max) & $97-173$ & $90-175$ \\
Surgery type: $\mathrm{n}(\%)$ & & \\
\hline Elective & $111(82.2)$ & $112(82.6)$ \\
In-house urgent & $24(17.8)$ & $23(17.4)$ \\
\hline
\end{tabular}

${ }^{*}$ One patient had a baseline haemoglobin $(\mathrm{Hb})$ of $95 \mathrm{~g} / \mathrm{L}$ at randomisation, which had fallen to 83 immediately prior to surgery. This $\mathrm{Hb}$ drop was not identified until after surgery and the patient continued in the trial with their data included in the analyses based on the intention-to-treat principle. differences for $\mathrm{FEV}_{1}$ and $\mathrm{FVC}$ were statistically significant at 4 days post surgery; $-171 \mathrm{~mL}(95 \%$ CI -265 to -77 ; $\mathrm{p}=0.0004)$ and $-130 \mathrm{~mL}(95 \%$ CI -269 to $0 ; \mathrm{p}=0.0498$ ), respectively, after adjusting for baseline $\mathrm{FEV}_{1}, \mathrm{FVC}$ and randomisation factors (online supplemental material).

\section{Hospital length of stay}

The mean time to patients being fit for hospital discharge following index surgery was similar between groups. The mean postoperative hospital length of stay was 7.4 (SD 7.5 , range $3-79$ ) in the mini group, and 6.3 days (SD 3.2, range $3-31$ ) in the conventional (online supplemental material).

\section{Postoperative valve function}

The distribution of valve types and valve sizes by group was similar; mean valve size inserted was $23 \mathrm{~mm}$ in the mini group and $24 \mathrm{~mm}$ in the conventional (table 5, figures 2 and 3). Over $70 \%$ of patients in each group received a tissue valve, over $25 \%$ received a mechanical valve and $2 \%-3 \%$ received a sutureless tissue valve.

Postoperative transthoracic echo showed a similar decrease in mean aortic valve gradient in both groups to $16 \mathrm{~mm} \mathrm{Hg}$; peak gradient decreased to $30 \mathrm{~mm} \mathrm{Hg}$ in both groups (table 5); 6/134 patients had moderate or severe aortic regurgitation in the mini group compared with $3 / 130$ in the conventional (table 5). Only two patients in the trial, one in each arm, suffered a paravalvular leak; both were severe. One of these patients, in the mini sternotomy arm, had a sutureless valve prosthesis. Seven further patients had moderate regurgitation; these were all intravalvular leaks. Transoesophageal echo was performed in all patients prior to leaving the operating theatre.

\section{Adverse events}

There were no in-hospital deaths in either group. At 12 weeks follow-up, there were four deaths; two in each arm of the study. Adverse events in each group were broadly similar and within acceptable clinical limits. By 12 weeks, 4/135 patients in the mini-sternotomy group and $1 / 135$ in the conventional group had suffered a stroke (defined as a persistent neurological deficit). Atrial arrhythmias were identified in $61 / 135$ patients in the mini group and 51/135 in the conventional. By 12 weeks, 11/135 patients in the mini group and 3/135 patients in the conventional had a sternal wound infection (online supplemental material).

\section{Quality of life, costs and cost-effectiveness}

Costs during the index admission were significantly greater for the mini group (mini-conventional: mean difference $£ 1140$; 95\% CI 303 to 1977), primarily reflecting the additional cost of theatre time (online supplemental material). Overall costs were not significantly different (mini-conventional: mean difference $£ 746 ; 95 \%$ CI -245 to 1737). There was no significant difference in quality of life between groups up to 12 weeks (mini-conventional: mean difference area under curve -0.009 QALYs; $95 \%$ CI 0.020 to 0.002). Although differences 
Table 2 The number and proportion of patients receiving a red cell transfusion*, and the number of units received, to 7 days and to discharge following index surgery, by group

\begin{tabular}{|c|c|c|c|c|}
\hline & $\begin{array}{l}\text { Mini-sternotomy } \\
\text { group }\end{array}$ & $\begin{array}{l}\text { Conventional } \\
\text { sternotomy group }\end{array}$ & OR (95\% Cl; p value) & $\begin{array}{l}\text { Risk difference } \\
\text { (95\% Cl; p value) }\end{array}$ \\
\hline \multicolumn{5}{|l|}{ Red cell transfusions } \\
\hline $\begin{array}{l}\text { Postoperatively to } 7 \text { days number of } \\
\text { patients (\%) }\end{array}$ & 23/135 (17.0) & 23/135 (17.0) & 1.0 (0.5 to $2.0 ; 0.9052)$ & $\begin{array}{l}0.0(-0.1 \text { to } 0.1 \\
0.9999)\end{array}$ \\
\hline $\begin{array}{l}\text { Postoperatively to discharge number of } \\
\text { patients (\%) }\end{array}$ & $34 / 135$ (25.2) & $29 / 135(21.5)$ & $1.4(0.7$ to 2.7$)$ & \\
\hline Mean \pm SD & $1.6 \pm 0.7$ & $2.3 \pm 1.7$ & & \\
\hline Range (min-max) & $1-3$ & $1-9$ & & \\
\hline \multicolumn{5}{|l|}{ Red cell units - postoperatively to discharge } \\
\hline Number of patients & $34 / 135$ & $29 / 135$ & & \\
\hline
\end{tabular}

${ }^{*}$ Reprinted from Hancock et al, ${ }^{28}$ with permission from Elsevier.

in costs and quality of life were not individually significant, the bivariate cost-QALY distribution (combining these two) suggests conventional surgery might be more cost-effective (figure 4). In the base-case model, mini was dominated by conventional surgery (due to greater cost and less benefit), with only a $5.8 \%$ probability of being cost-effective at a willingness to pay of $£ 20000 /$ QALY (table 6).

\section{Sensitivity and subgroup analyses}

There was no significant surgeon effect; the odds of receiving a red cell transfusion for two patients treated by the same surgeon compared with two patients treated by different surgeons was 1.2 (95\% CI 0.9 to 1.6 ; $\mathrm{p}=0.1379$ ).
Protocol deviations in respect of cell tranfusions did not affect the results of the primary analysis; excluding these patients produced the same results as those from the intention-to-treat analysis.

\section{DISCUSSION}

\section{Main findings}

Mini-sternotomy was not superior to conventional sternotomy with respect to red cell transfusion requirements within 7 days of surgery. Analysis of secondary endpoints showed a statistically significant difference in transfusion volumes of non-red cell blood components. Aortic

Table 3 The number and proportion of patients receiving a non-red cell transfusion, and the number of units received, to 7 days and to discharge following index surgery, by group

\begin{tabular}{|c|c|c|c|}
\hline & $\begin{array}{l}\text { Mini-sternotomy } \\
\text { group }\end{array}$ & $\begin{array}{l}\text { Conventional sternotomy } \\
\text { group }\end{array}$ & OR (95\% Cl p value) \\
\hline \multicolumn{4}{|l|}{ Non-red cell transfusions } \\
\hline Postoperatively to 7 days number of patients (\%) & $6 / 135(4.4)$ & $18 / 135(13.3)$ & 0.3 (0.1 to $0.8 ; 0.0137)$ \\
\hline Postoperatively to discharge number of patients (\%) & $13 / 135(9.6)$ & $21 / 135(15.6)$ & $0.6(0.3$ to 1.2$)$ \\
\hline \multicolumn{4}{|l|}{ Non-red cell component units-postoperatively to 7 days } \\
\hline Number of patients & 6 & 18 & \\
\hline Range (min-max) & $2-5$ & $1-7$ & \\
\hline \multicolumn{4}{|l|}{ Non-red blood cell units-postoperatively to discharge } \\
\hline Number of patients & 13 & 21 & \\
\hline Mean \pm SD & $4.8 \pm 2.3$ & $4.9 \pm 2.3$ & \\
\hline Range (min-max) & $1-8$ & $1-12$ & \\
\hline
\end{tabular}


Table 4 Outcomes during index hospital stay for cardiopulmonary bypass and aortic cross-clamp times and drain losses

\section{Mini-sternotomy Conventional sternotomy Mean difference}

group $(n=135) \quad$ group $(n=135) \quad(95 \% \mathrm{Cl} ; \mathrm{p}$ value $)$

\begin{tabular}{|c|c|c|c|}
\hline \multicolumn{4}{|c|}{ Cardio pulmonary bypass time (min) } \\
\hline Mean \pm SD & $82.7 \pm 23.5$ & $59.6 \pm 15.1$ & \\
\hline Range (min-max) & $41.0-199$ & $37.0-170.0$ & \\
\hline \multicolumn{4}{|c|}{ Aortic cross-clamp time (min) } \\
\hline Mean \pm SD & $64.1 \pm 17.1$ & $46.3 \pm 10.7$ & \\
\hline Range (min-max) & $32.0-132.0$ & $32.0-97.0$ & \\
\hline \multicolumn{4}{|c|}{ Drain losses at 12 hours } \\
\hline Mean \pm SD & $181.6 \pm 138.7$ & $306.9 \pm 348.6$ & $-127.7(-191.7$ to $-63.8 ; 0 \cdot 0001)$ \\
\hline Range (min-max) & $25-925$ & $25-3000$ & \\
\hline \multicolumn{4}{|c|}{ Drain losses at drain removal } \\
\hline Mean \pm SD & $251.7 \pm 198.4$ & $393.7 \pm 378.7$ & $-145.3(-218.1$ to $-72.3 ; 0 \cdot 0001)$ \\
\hline Range (min-max) & $25-1425$ & $50-3000$ & \\
\hline
\end{tabular}

valve size and postoperative function were comparable in the two groups. Mini-sternotomy resulted in a relative reduction in chest drain losses; however, higher blood loss in the conventional group did not translate into red cell transfusions. Mini patients had substantially longer bypass and cross-clamp times and worse lung function at 4 days post surgery. Lung function at 12 weeks and adverse event rates were otherwise not different between groups. Conventional sternotomy was found to be more costeffective. MAVRIC findings contradict those from other trials that pre-date it. ${ }^{23}{ }^{24}$ Two 100 patient RCTs published since MAVRIC and the systematic review do not alter the discussion. ${ }^{2526}$ Both found no difference in major clinical outcomes and findings relating to shorter hospital stay in mini-sternotomy; a reduction in bleeding through chest drains and mean difference in EQ-5D scores at baseline and at 6 weeks ${ }^{25}$ are consistent with MAVRIC findings.

\section{Strengths and limitations}

This is the largest single trial to have compared minimally invasive sternotomy to conventional median sternotomy for AVR. A recent Cochrane review identified 511 patients from 7 previous RCTs. ${ }^{7}$ In MAVRIC, the mini-sternotomy technique divided only the manubrium and is therefore less invasive than other minimally invasive techniques. The trial was undertaken by three experienced minimally invasive surgeons who were expert at both techniques. Patients were blinded to group allocation until 2 days following index surgery, reducing the likelihood of bias. The trial recruited a significant proportion of eligible patients; 274/313 (86\%), with few requiring conversion to conventional sternotomy, increasing the likelihood that the trial findings are generalisable. A further strength was the detailed health economic evaluation; this has not been performed previously.

The trial had some limitations, including the single centre design. This will tend to have biased treatment effect estimates away from the null, which is at odds with our observed effect. There were no significant levels of protocol non-adherence, with no effect on the main trial finding. The event rate for the primary outcome was much lower than expected at $17 \%$; nationally red cell transfusion rates following valve surgery are $46 \cdot 4 \% .{ }^{27}$ In our pretrial audit conducted over 5 years, ending 2009, $30 \%$ of mini-sternotomy patients received a red cell transfusion. We attribute the observed transfusion rate in MAVRIC to the restrictive red cell transfusion threshold applied; this followed evidence at the time of trial design. The consultant (expert) led nature of the trial interventions is also likely to have reduced the need for transfusions postoperatively and to have biased trial results towards the null.

\section{Clinical importance}

MAVRIC contributes important evidence to the minimally invasive AVR evidence base, summarised in a Cochrane review. ${ }^{7}$ MAVRIC demonstrated longer cross-clamp and bypass times with the manubrium-limited ministernotomy, attributed to known differences between the interventions. Minimally invasive techniques in MAVRIC required a number of surgical steps to be performed with the aortic clamp in place (drain insertion and pacing wire insertion, for example), meaning cross-clamp and bypass were longer. This is not an absolute requirement in other minimally invasive approaches; for example, where the incision is extended into the body of the sternum or where rapid deployment valves are used, there are no differences in cross-clamp and bypass times. ${ }^{7}$

The size of MAVRIC and event rate prevents formal comparison of adverse events between the groups, of note is the difference in stroke rate; this would benefit from exploration in a future trial.

The cost-effectiveness plane indicates that conventional surgery is less costly and more beneficial than minimally invasive surgery; contact with healthcare professionals was greater in the mini group, although there was no clear pattern of use. Wide CIs mean that differences are 
Table 5 Outcomes during index hospital stay for valve size and type, and for valve function and regurgitation to 6 weeks by group

\begin{tabular}{|c|c|c|c|}
\hline $\begin{array}{l}\text { Valve } \\
\text { characteristics }\end{array}$ & $\begin{array}{l}\text { Mini- } \\
\text { sternotomy } \\
\text { group } \\
(n=135)\end{array}$ & $\begin{array}{l}\text { Conventional } \\
\text { sternotomy } \\
\text { group }(n=135)\end{array}$ & $\begin{array}{l}\text { Mean } \\
\text { difference } \\
\text { ( } 95 \% \text { Cl; } p \text { value) }\end{array}$ \\
\hline \multicolumn{4}{|l|}{ Valve size: $\mathrm{mm}$} \\
\hline 19-21 mm n (\%) & $40(29.6)$ & $38(28.1)$ & \\
\hline 23-25 mm n (\%) & $84(62.2)$ & 80 (59.3) & \\
\hline 27-29 mm n (\%) & $11(8.2)$ & $17(12.6)$ & \\
\hline Mean \pm SD & $23.1 \pm 2.1$ & $23.6 \pm 2.5$ & \\
\hline $\begin{array}{l}\text { Range (min- } \\
\max \text { ) }\end{array}$ & 19.0-29.0 & $19.0-31.0$ & \\
\hline
\end{tabular}

Valve type: $\mathrm{n}$

(\%)

Biological and $\quad 4(3.0) \quad 3(2.2)$ sutureless

\begin{tabular}{lll}
$\begin{array}{l}\text { Biological } \\
\text { prosthesis }\end{array}$ & $96(71.1)$ & $98(72.6)$ \\
$\begin{array}{l}\text { Mechanical } \\
\text { prosthesis }\end{array}$ & $35(25.9)$ & $34(25.2)$ \\
\hline
\end{tabular}

\begin{tabular}{|c|c|c|c|}
\hline \multicolumn{4}{|l|}{ Valve function } \\
\hline \multicolumn{4}{|l|}{ Mean gradient } \\
\hline \multicolumn{4}{|l|}{ Baseline } \\
\hline $\mathrm{n}$ & $111^{*}$ & $110^{*}$ & \\
\hline Mean $\pm S D$ & $47.9 \pm 15.7$ & $47.7 \pm 20.2$ & $0.2(-4.6$ to 5.0$)$ \\
\hline Min-max & $10-93$ & $8-110$ & \\
\hline \multicolumn{4}{|l|}{6 weeks } \\
\hline $\mathrm{n}$ & $120^{\star}$ & $126^{\star}$ & \\
\hline Mean \pm SD & $15.7 \pm 5.5$ & $15.7 \pm 5.8$ & $0.5+(-1.0$ to 2.1$)$ \\
\hline Min-max & 6-33 & 4-34 & \\
\hline Peak gradien & & & \\
\hline
\end{tabular}

\begin{tabular}{|c|c|c|c|}
\hline$n$ & $125^{\star}$ & $124^{\star}$ & \\
\hline Mean \pm SD & $82.3 \pm 25.9$ & $77.1 \pm 29.1$ & $5.2(-1.7$ to 2.3$)$ \\
\hline Min-max & $16-152$ & $8-173$ & \\
\hline \multicolumn{4}{|l|}{6 weeks } \\
\hline $\mathrm{n}$ & $130^{*}$ & $130^{*}$ & \\
\hline Mean \pm SD & $29.9 \pm 10.5$ & $29.7 \pm 10.8$ & $-0.3 \dagger(-2.9$ to 2.3$)$ \\
\hline Min-max & $12-62$ & $11-61$ & \\
\hline \multicolumn{4}{|l|}{$\begin{array}{l}\text { Aortic valve } \\
\text { regurgitation }\end{array}$} \\
\hline \multicolumn{4}{|l|}{ Nil/trivial } \\
\hline $\mathrm{n} / \mathrm{n}(\%)$ & $\begin{array}{l}109 / 134^{*} \\
(81.3)\end{array}$ & $109 / 130 *(83.8)$ & 218/264 (82.6) \\
\hline \multicolumn{4}{|l|}{ Mild } \\
\hline $\mathrm{n} / \mathrm{n}(\%)$ & $19 / 134^{*}(14.2)$ & $18 / 130 *(13.9)$ & $37 / 264(14.0)$ \\
\hline \multicolumn{4}{|l|}{ Moderate } \\
\hline $\mathrm{n} / \mathrm{n}(\%)$ & $5 / 134^{\star}(3.7)$ & $2 / 130^{*}(1.5)$ & $7 / 264$ (2.7) \\
\hline \multicolumn{4}{|l|}{ Severe } \\
\hline n/n (\%) & $1 / 134^{*}(0.8)$ & $1 / 130^{\star}(0.8)$ & 2/264 (0.8) \\
\hline
\end{tabular}

*It was not possible to quantify valve function in all patients.

†After adjusting for randomisation factors and baseline data.

imprecise. MAVRIC does not support the use of funds to expand AVR via manubrium-limited mini-sternotomy practice.

\section{Mini-sternotomy}

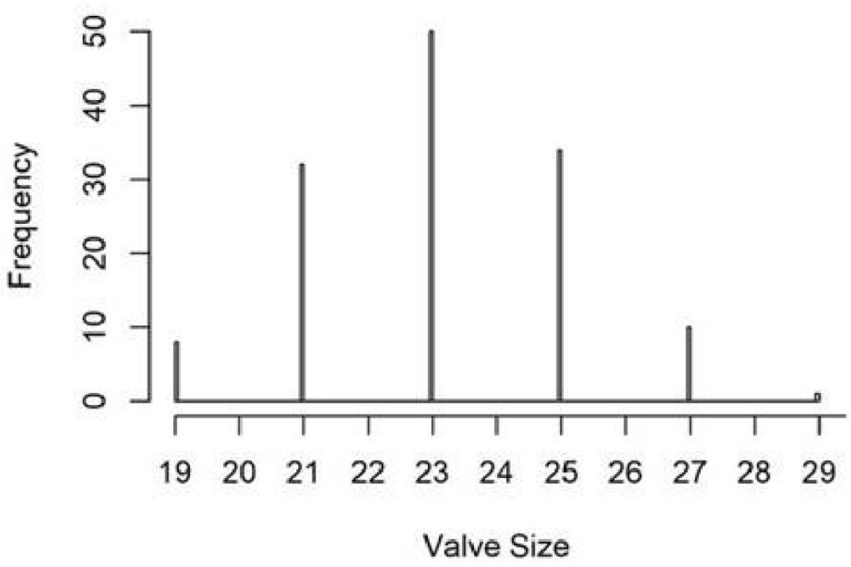

Figure 2 Valve size distribution: mini-sternotomy group.

\section{Conventional sternotomy}

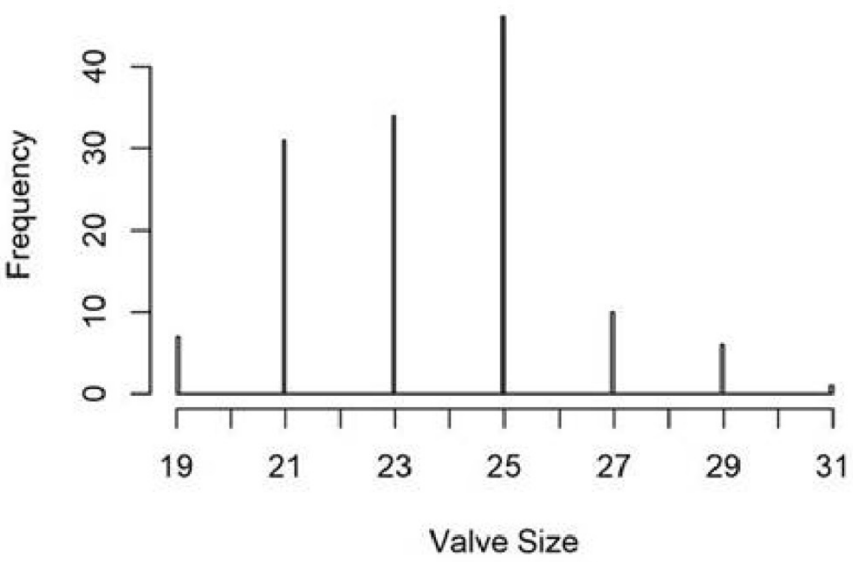

Figure 3 Valve size distribution: conventional sternotomy group.

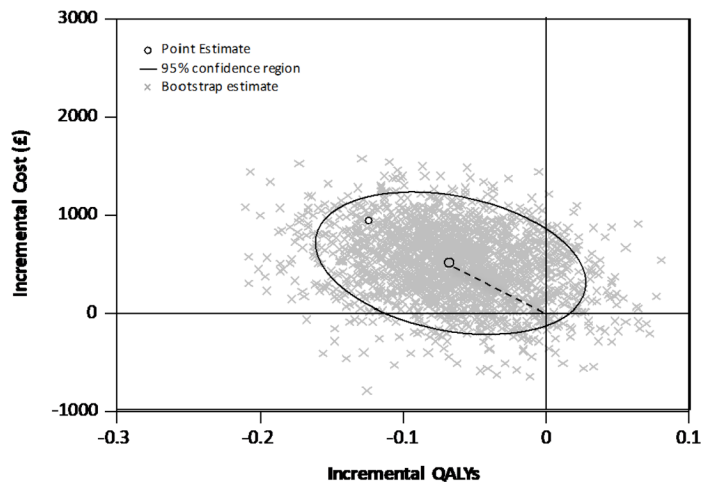

Figure 4 Cost-effectiveness plane, cost/QALY (£): ministernotomy versus conventional surgery.

MAVRIC, the world's largest RCT at low risk of bias, found no additional clinical benefit, in terms of red blood cell transfusion rates of minimally invasive AVR. Results are in agreement with the findings of a Cochrane review of trials that have evaluated mini-sternotomy AVR. ${ }^{7}$ This information should be disseminated to patients, 
Table 6 Cost-effectiveness, cost/QALY (£): mini-sternotomy versus conventional surgery

\begin{tabular}{|c|c|c|c|c|c|}
\hline Model & $\begin{array}{l}\text { Incremental cost }(95 \% \\
\mathrm{Cl})\end{array}$ & Incremental QALYs (95\% Cl) & ICER (95\% Cl) & P value* & $P$ value \\
\hline $\begin{array}{l}\text { Multiple imputation, } \\
\text { covariate adjusted } \neq\end{array}$ & $508(-202$ to 1217$)$ & $-0.007(-0.016$ to 0.002$)$ & Dominated§ & 0.058 & 0.052 \\
\hline $\begin{array}{l}\text { Complete case, covariate } \\
\text { adjusted } \neq\end{array}$ & $630(25$ to 1224$)$ & $-0.007(-0.016$ to 0.002$)$ & Dominated & 0.013 & 0.011 \\
\hline
\end{tabular}

*Probability cost-effective or net monetary benefit if willing to pay $£ 20000 / \mathrm{QALY}$.

†Probability cost-effective or net monetary benefit if willing to pay $£ 30000 / Q A L Y$.

$\ddagger$ Regression estimates adjusted for trial stratifying covariates and baseline EQ-5D.

$\S$ Dominance indicates average costs were less and average benefit greater for conventional surgery.

clinicians and commissioners to inform decisions about AVR surgery including commissioning.

\section{Author affiliations}

${ }^{1}$ Newcastle Clinical Trials Unit, Newcastle University, Newcastle upon Tyne, UK

${ }^{2}$ Wolfson Research Institute for Health and Wellbeing, Durham University, Stocktonon-Tees, Durham, UK

${ }^{3}$ Warwick Medical School, University of Warwick, Coventry, UK

${ }^{4}$ Department of Cardiovascular Sciences and NIHR Leicester Biomedical Research Unit in Cardiovascular Medicine, University of Leicester, Leicester, UK

${ }^{5}$ Department of Cardiothoracic Surgery, James Cook Hospital, South Tees Hospitals NHS Foundation Trust, Middlesbrough, UK

Acknowledgements We are grateful to the patients who agreed to take part in the MAVRIC trial. This trial would not have been possible without the support of all staff in the Cardiothoracic Services in The James Cook University Hospital. We would like to thank Heather Robinson and Jonathan Broughton for their assistance with recruitment, data collection and data entry. We would like to thank the team at the Clinical Trials Unit, including Jennifer Wilkinson, Andrew Thorpe, Leanne Marsay and Catherine Frost for their work in managing the trial and its data.

Contributors $\mathrm{EA}, \mathrm{HCH}, \mathrm{RHM}, \mathrm{JM}$, and GM designed the trial and sought funding. $E A, A G$ and WAO recruited patients to the trial and performed surgery. AK conducted the statistical analysis and JM conducted the health economic analysis. All authors contributed to the final manuscript.

Funding This work was supported by the NIHR Research for Patient Benefit Programme (grant number PB-PG-1112-29035).

Disclaimer The views and opinions expressed are those of the authors and do not necessarily reflect those of the National Institute for Health Research (NIHR) Research for Patient Benefit Programme, the National Health Service or the Department of Health and Social Care.

Competing interests GM: Declares research grant funding from Zimmer Biomet for a trial of blood transfusion. He is supported by the British Heart Foundation (CH/12/1/29419) and the NIHR Leicester Biomedical Research Centre. HCH, RHM, AK, JM, AG, WAO and EA: None.

Patient consent for publication Not required.

Provenance and peer review Not commissioned; externally peer reviewed.

Data availability statement Data are available in a public, open access repository. Anonymised data from this study may be available to the scientific community subject to appropriate ethical approval. Requests for data should be directed to the senior author.

Supplemental material This content has been supplied by the author(s). It has not been vetted by BMJ Publishing Group Limited (BMJ) and may not have been peer-reviewed. Any opinions or recommendations discussed are solely those of the author(s) and are not endorsed by BMJ. BMJ disclaims all liability and responsibility arising from any reliance placed on the content. Where the content includes any translated material, BMJ does not warrant the accuracy and reliability of the translations (including but not limited to local regulations, clinical guidelines, terminology, drug names and drug dosages), and is not responsible for any error and/or omissions arising from translation and adaptation or otherwise.

Open access This is an open access article distributed in accordance with the Creative Commons Attribution Non Commercial (CC BY-NC 4.0) license, which permits others to distribute, remix, adapt, build upon this work non-commercially, and license their derivative works on different terms, provided the original work is properly cited, appropriate credit is given, any changes made indicated, and the use is non-commercial. See: http://creativecommons.org/licenses/by-nc/4.0/.

ORCID iDs

Helen C Hancock http://orcid.org/0000-0002-1494-8551

Rebecca H Maier http://orcid.org/0000-0002-7350-3288

W Andrew Owens http://orcid.org/0000-0001-9836-9209

Enoch Akowuah http://orcid.org/0000-0002-2429-3579

\section{REFERENCES}

1 Matiasz R, Rigolin VH. 2017 focused update for management of patients with valvular heart disease: summary of new recommendations. J Am Heart Assoc 2018.

2 National adult cardiac surgery audit 2020 summary report 2016.

3 Blue Book Online. The Society for Cardiothoracic Surgery in Great Britain \& Ireland. Available: http://bluebook.scts.org/\# [Accessed 23 Jul 2018].

4 Leontyev S, Walther T, Borger MA, et al. Aortic valve replacement in octogenarians: utility of risk stratification with EuroSCORE. Ann Thorac Surg 2009;87:1440-5.

5 Phan K, Xie A, Di Eusanio M, et al. The Collaborative Research (CORE) group. meta-analysis of minimally invasive versus conventional sternotomy for aortic valve replacement. Ann Thorac Surg 2014;98:1499-511.

6 Ghanta RK, Lapar DJ, Kern JA, et al. Minimally invasive aortic valve replacement provides equivalent outcomes at reduced cost compared with conventional aortic valve replacement: a real-world multi-institutional analysis. J Thorac Cardiovasc Surg 2015;149:1060-5.

7 Kirmani BH, Jones SG, Malaisrie SC, et al. Limited versus full sternotomy for aortic valve replacement. Cochrane Database Syst Rev 2017;4:CD011793.

8 Fujita B, Ensminger S, Bauer T, et al. Trends in practice and outcomes from 2011 to 2015 for surgical aortic valve replacement: an update from the German Aortic Valve Registry on 42776 patients. Eur J Cardiothorac Surg 2018;53:552-9.

9 Lehmann S, Merk DR, Etz CD, et al. Minimally invasive aortic valve replacement: the Leipzig experience. Ann Cardiothorac Surg 2015;4:49-56.

10 Johnston DR, Roselli EE. Minimally invasive aortic valve surgery: Cleveland clinic experience. Ann Cardiothorac Surg 2015;4:140-7.

11 Patel NN, Avlonitis VS, Jones HE, et al. Indications for red blood cell transfusion in cardiac surgery: a systematic review and metaanalysis. Lancet Haematol 2015;2:e543-53.

12 Chen Q-H, Wang H-L, Liu L, et al. Effects of restrictive red blood cell transfusion on the prognoses of adult patients undergoing cardiac surgery: a meta-analysis of randomized controlled trials. Crit Care 2018;22:142. 
13 Pagano D, Milojevic M, Meestersa MI. The task force on patient blood management for adult cardiac surgery of the European Association for Cardio-Thoracic Surgery (EACTS) and the European Association of Cardiothoracic Anaesthesiology (EACTA). EACTS/ EACTA guidelines on patient blood management for adult cardiac surgery. Eur J Cardio-Thorac Surg 2018;53:79-111.

14 Dixon JR. The International Conference on Harmonization Good Clinical Practice guideline. Qual Assur 1998;6:65-74.

15 Akowuah E, Goodwin AT, Owens WA, et al. Manubrium-limited ministernotomy versus conventional sternotomy for aortic valve replacement (MAVRIC): study protocol for a randomised controlled trial. Trials 2017; 18:46.

16 NICE. Guide to the methods of technology appraisal. London: National Institute for Health and Care Excellence, 2013.

17 NHS reference costs 2015-16. London: department of health 2016.

18 Curtis L, Burns A. Unit costs of health and social care 2015. the University of Kent: Canterbury, 2015.

19 Sterne JAC, White IR, Carlin JB, et al. Multiple imputation for missing data in epidemiological and clinical research: potential and pitfalls. BMJ 2009;338:b2393.

20 White IR, Horton NJ, Carpenter J, et al. Strategy for intention to treat analysis in randomised trials with missing outcome data. BMJ 2011;342:d40.
21 Faria R, Gomes M, Epstein D, et al. A guide to handling missing data in cost-effectiveness analysis conducted within randomised controlled trials. Pharmacoeconomics 2014;32:1157-70.

22 White IR, Royston P, Wood AM. Multiple imputation using chained equations: issues and guidance for practice. Stat Med 2011;30:377-99.

23 Aris A, Cámara ML, Montiel J, et al. Ministernotomy versus median sternotomy for aortic valve replacement: a prospective, randomized study. Ann Thorac Surg 1999;67:1583-7.

24 Moustafa MA, Abdelsamad AA, Zakaria G, et al. Minimal vs median sternotomy for aortic valve replacement. Asian Cardiovasc Thorac Annals 2007:15:472-5.

25 Rodríguez-Caulo EA, ArantzaGuzón A, Otero-Forero J, et al. Quality of life after ministernotomy versus full sternotomy aortic valve replacement.

26 Vukovic PM, Milojevic P, Stojanovic I, et al. The role of ministernotomy in aortic valve surgery-a prospective randomized study. J Card Surg 2019;34:435-9.

27 National comparative audit of blood transfusion. Available: http:// hospital.blood.co.uk/media/26859/nca-2011_use_of_blood_in_adult cardiac_surgery_report.pdf [Accessed 23 Jul 2018].

28 Hancock HC, Maier RH, Kasim AS, et al. Mini-sternotomy versus conventional sternotomy for aortic valve replacement. J Am Coll Cardiol 2019;73:2491-2. 